\title{
PARA UNA CARACTERIZACIÓN HISTÓRICA DEL VANGUARDISMO LITERARIO HISPANOAMERICANO
}

\author{
Por \\ NELSON OSORIO T. \\ Centro de Estudios Latinoamericanos \\ "Rómulo Gallegos", \\ Caracas
}

Un aspecto interesante $-\mathrm{y}$ del que, a mi juicio, no se han sacado todas las consecuencias - que presenta la llamada Vanguardia artística y literaria de los comienzos de este siglo ${ }^{1}$ es su condición de fenómeno internacional. ${ }^{2}$ Esta condición internacional que muestra su existencia no es incompatible, sin embargo, con la gran variedad de formas concretas que puedan asumir sus manifestaciones en las distintas realidades nacionales y culturales.

Esta dialéctica esencial del fenómeno plantea una de las primeras dificultades para su estudio, ya que al no ser tomada debidamente en cuenta se corre el riesgo de caer o en una consideración empírica y descriptiva de su pluralidad - lo que hace perder de vista la integridad en beneficio de un catálogo taxonómico muchas veces irrelevante-o en una abstracta reducción generalizadora que dificulta el captar la riqueza y pluralidad concreta de sus múltiples variantes. Y si a veces los árboles impiden ver el bosque, también lo contrario suele suceder.

1 En este trabajo nos referimos a la Vanguardia en su dimensión histórica, en cuanto peculiar sesgo de la renovación artística que en los primeros decenios del siglo XX inicia la literatura contemporánea.

2 Al respecto puede consultarse el interesante trabajo de Miklós Szabolcsi "La 'vanguardia' literaria y artística como fenómeno internacional" (1967), reproducido en Casa de las Américas, La Habana, XII, 74, septiembre-octubre de 1972, p. 4-17. Relacionado con esto se da también el caso de escritores que participan en los movimientos de vanguardia en otras lenguas, y que en nuestro continente no han sido suficientemente estudiados; aparte del caso más conocido de Vicente Huidobro habría que considerar los de Alfredo Gangotena en Ecuador, Juan Emar en Chile, César Moro en Perú y otros. Por ser casi desconocido y extramadamente curioso cabe mencionar al húngaro Zsigmond Remenyik; este participa en 1920 en la vanguardia húngara exiliada en Viena; posteriormente publica textos vanguardistas en castellano mientras vive en Chile y en Perú, y firma en Valparaiso uno de los primeros manifiestos vanguardistas chilenos: "Rosa Náutica" (Cfr. Georges Ferdinandy; L'oeuvre hispano-ámericaine de Zsigmond Remenhik, Strasbourg, 1969, 265 - XX p. Mimeografiado). Debo este texto de la tesis de Ferdinandy a la generosa amistad del hispanista húngaro Matýas Horanyi. Existe una edición impresa por Mouton/De Gruyter, 1975, 190 pp. 
En Hispanoamérica, la tendencia historiográfica que ha dominado en el estudio de este fenómeno ha tenido un marcado carácter deductivo: tomando como medida y modelo las manifestaciones más prestigiadas de las vanguardias en Europa occidental, y a partir de ciertas escuelas canónicas (Futurismo, Cubismo, Dadaísmo, Expresionismo, Surrealismo especialmente) y del registro de sus resonancias en algunas obras y autores del continente, se forma un catálogo al que se reduce el "vanguardismo" en nuestro medio. ${ }^{3}$ Esto implica, en último término, una perspectiva ideológica no explicitada que considera el Vanguardismo hispanoamericano como un injerto artificial, como un simple epifenómeno de la cultura europea, sin verdadera raigambre en condiciones objetivas de la realidad continental.

En los últimos años, sin embargo, y como parte de un cuestionamiento crítico de la historiografía literaria institucionalizada, han surgido propuestas que intentan establecer la legitimidad y propiedad de las tendencias de Vanguardia en nuestra producción literaria de los años 2030. De lo que se trata es de comprenderlas globalmente en función del surgimiento en el continente - a partir sobre todo de la crisis de la Primera Guerra Mundial- de condiciones históricas nuevas, que no sólo afectan internamente a los países latinoamericanos sino que además, en lo externo, significan un profundo cambio cualitativo en su modo de inserción a un sistema internacional.

Por ser la literatura un fenómeno de la vida social -cuestión que si bien es frecuentemente soslayada nadie, que sepamos, pone en duda-, es legítimo el intento de tratar de examinar la relación que pueda haber entre este aspecto del fenómeno de las vanguardias literarias - es decir, su internacionalización y expansión mundial- con las nuevas condiciones económicas, sociales, políticas y culturales que entra a vivir la humanidad a comienzos del siglo XX, condiciones que de una manera u otra, en mayor o menor grado, afectan a todos los países, incluidos los de nuestro

3 Un estudio especial merecería el modo como han sido considerados los casos del Ultraísmo y del Creacionismo al examinarse el conjunto de la vanguardia hispanoamericana. A veces se les agrega a la lista de ismos de la época como una escuela más de vanguardia (por ejemplo, en el trabajo de Merlin H. Forster "Latin American Vanguardismo: Chronology and Terminology", en M.H. F., ed.: Tradition and Renewal. Chicago: University of Illinois Press, 1975), pero también se suele privilegiar a una u otra escuela poética como defínición global del vanguardismo hispanoamericano. Para Guillermo de Torre, en la versión actualizada de su libro de 1925 , la vanguardia hispanoamericana no constituye sino una prolongación del Ultraísmo, por lo que todas las referencias que a ella hace las incorpora al capítulo donde estudia dicho movimiento (Cf. G. de Torre, Historia de las literaturas de vanguardia. Madrid: Ediciones Guadarrama, 1966, p. 582 y ss.). Algo parecido hace Antonio de Undurraga, pero con el Creacionismo, bajo cuya influencia y proyección coloca prácticamente a todas las manifestaciones vanguardistas de la época (Cf. su "Teoría del Creacionismo", en la antología de Vicente Huidobro Prosa y poesía. Madrid: Aguilar, 1967, esp. p. 86 y ss). 
continente. Y para el caso de América Latina, también es legítimo postular una relación entre la formación y desarrollo de un Vanguardismo hispanoamericano como parte de un fenómeno internacional, y la nueva etapa de "internacionalización" de las condiciones históricas de la vida del continente, etapa en la cual éste es integrado de un modo nuevo y específico al sistema económico mundial que se reordena y surge a partir de la guerra del 14.

La Primera Guerra Mundial, pese a que involucra directamente en el conflicto a sólo seis países, afecta profundamente a todas las naciones, patentizando así la existencia de un orden internacional orgánico e interdependiente. No es aventurado, por lo mismo, sostener que su desarrollo y consecuencias marcan de tal manera la fisonomía del mundo que es posible tomar ese momento (1914-1918) como referencia cronológica para indicar el cierre de una etapa y el inicio de otra en la historia de la humanidad. Por eso puede decirse, en términos generales, que el verdadero comienzo de la contemporaneidad no está señalado por el límite cronológico de la centuria sino más bien por el hito que establece la guerra de 1914-1918 , primera gran crisis de un sistema que se había venido formando en función del capitalismo internacionalizado.

Hasta ese momento, bien o mal, el equilibrio del mundo se cimentaba en el predominio de las potencias de Europa occidental en el control y manejo de los asuntos internacionales. Por otra parte, en la vida interna de las sociedades nacionales, la estabilidad se basaba en la hegemonía de los dueños de los medios de producción sobre el conjunto de la vida de un país, hegemonía que, cualquiera fuera la forma política que revistiera, no había logrado ser desplazada.

Son precisamente estos dos pilares los que se resquebrajan en esos años de la guerra. El primero de ellos, porque a raíz del conflicto bélico los Estados Unidos de Norteamérica comienzan a asumir un papel decisivo en la nueva organización de la hegemonía mundial, y las potencias tradicionales que hasta entonces lo detentaban, seriamente afectadas durante y después del mismo, se ven obligadas a participar en la nueva distribución bajo condiciones también nuevas. El segundo, porque en la lejana Rusia un movimiento revolucionario de obreros y campesinos pobres, en 1917, en plena guerra, toma el poder y se dispone a destruir la hegemonía de las clases dominantes y a construir una sociedad sin

4 En tal sentido se pronuncia también Arnold Hauser, cuando sostiene que "el 'siglo XX' comienza después de la primera guerra mundial, es decir, en los años veinte" (Historia social de la literatura y el arte, 3a. ed., Madrid: Guadarrama, 1964, tomo III, p. 465). 
precedentes sobre bases nuevas que eliminaban la explotación patronal del trabajo asalariado 5 .

Las proyecciones y consecuencias de estos dos hechos marcan y determinan fundamentalmente el carácter del desarrollo del mundo contemporáneo.

A partir de la Primera Guerra Mundial, el proceso de internacionalización capitalista de la vida económica de las naciones, que se había venido constituyendo y consolidando desde el siglo pasado (y que es precisamente lo que hace que dicha guerra pueda ser calificada en propiedad de términos como "mundial"), entra en una nueva fase, superior y cualitativamente distinta. Por otra parte, las perspectivas que abre la revolución rusa de 1917 y la repercusión internacional que inmediatamente tiene, hacen brotar fermentos revolucionarios en las masas de trabajadores y en la intelectualidad progresista, no sólo en Europa sino en todo el mundo.

Por estas razones, en esos años no sólo se vive un período de crisis económica internacional sino que los conflictos y luchas sociales que ésta genera adquieren una dimensión política nueva y agresiva, y se empieza a vivir una etapa generalizada de cuestionamiento de los sistemas económicos, políticos e ideológicos dominantes.

En estas condiciones, no es difícil comprender que en muchos países la rebelión artística y el cuestionamiento de los valores culturales existentes se vincula en mayor o menor grado a los impulsos de revolución social que movilizan a los sectores explotados. Esto es lo que hace que en el proceso de renovación del arte y la literatura, la vanguardia artística (tradicionalmente encarnada por sectores aislados de las éticas culturales) tuviera objetivamente la posibilidad histórica de encuentro y coincidencia con la vanguardia política y social representada por las clases y sectores contestarios en ascenso. Probablemente pueda considerarse esta posibilidad - no siempre concretada y ni siquiera asumida conscientementecomo una de las condiciones que posibilitan el que la renovación vanguardista de esos años alcanzara una dimensión distinta, más amplia, profunda y hasta cierto punto "masiva" - en todo caso, menos elitesca-, lo que constituye un hecho prácticamente inédito en la historia de las renovaciones artístico-literarias.

Sin embargo, esta posibilidad de alcance de las vanguardias artísticas de esos años no se realiza plenamente en casi ningún país, y a menudo no se manifiesta sino en aproximaciones y coincidencias circunstanciales o

5 No estará de más insistir en que estos dos hechos fundamentales que caracterizan la contemporaneidad como nueva etapa histórica no surgen ex nihilo, de un modo demiúrgico, sino que son consecuencias del mismo desarrollo desequilibrado que venía acumulando contradicciones desde el siglo pasado ( $\mathrm{y}$ aún antes). La presión de algunas de esas contradicciones provoca la guerra, y la guerra posibilita la eclosión de otras. 
individuales $^{6}$. Esto es lo que explica el hecho de que, si bien no pueda hablarse de una general coincidencia entre los movimientos de vanguardia artística y los de vanguardia política y social, muchos de los más destacados representantes de la vanguardia artística de esos años se incorporan - aunque en algunos casos sólo sea temporalmente - a la crítica del sistema social e incluso a las luchas por el socialismo. Están entre otros, los ejemplos de Maiakovsky en Rusia, Vancura en Praga, Weill, Grosz y Brecht en Alemania, Aragón, Eluard en Francia, Attila József en Hungría, etc. ${ }^{7}$. Y en nuestro continente, los "estridentistas" mexicanos, Huidobro, Pablo de Rokha en Chile, el grupo de la Revista de Avance en Cuba, Oquendo de Amat en Perú, Luis Vidales en Colombia, Pío Tamayo en Venezuela, etc. Otra cosa, claro está, es la consecuencia y trayectoria posterior de ciertos escritores vanguardistas que se inician como contestatarios radicales y terminan renegando de sus primeras rebeldías ; pero esto no invalida el carácter de cuestionamiento generalizado, más allá de lo puramente artístico, que se encuentra en la base del impulso que nutre a las vanguardias.

En todo caso, lo que importa establecer es que las condiciones históricas que determinan la crisis de una época y el inicio de otra -que son las mismas que determinan en último término el surgimiento y el carácter de las tendencias de vanguardia en ese período--, tienen una dimensión y un alcance internacionales. Un examen de la realidad latinoamericana de esos

6 En nuestra América quien vislumbra con mayor claridad estas posibilidades es Mariátegui, a cuyos artículos sobre el tema habría que dedicarles mayor atención de la que han tenido hasta hoy.

$7 \mathrm{El}$ mejor conjunto de materiales que he podido consultar sobre este aspecto se encuentra en el volumen de la Academia de Ciencias de Eslovaquia que recoge los trabajos de la Conferencia sobre la Vanguardia Literaria que se celebró en Smolenice en octubre de 1965. El volumen, con casi medio centenar de ponencias (en eslovaco) ofrece un rico material para revalorar la significación histórica de la vanguardia literaria europea (oriental y occidental) de entreguerras, sobre todo en lo que respecta a su vinculación con las luchas democráticas y revolucionarias (Cf. Problémy literárnej avantgardy [Problemas de la vanguardia literaria], Bratislava: Slovenska Akademia Vied, 1969, 422 p.).

8 Es curioso que muchos de los vanguardistas literarios se inicien asumiendo posiciones criticas y rebeldes frente a la sociedad y terminen integrados al sistema e incluso defendiendo valores conservadores y hasta reaccionarios. A título de ejemplo algo descuidado se puede recordar que Jorge Luis Borges, hoy sostenedor de dictaduras militares y anticomunista orgánico, publica en 1920 en la revista Grecia de Sevilla (No 48, $1^{\circ}$ de septiembre de 1920) su poema "Rusia", en que habla de las trincheras, las muchedumbres y esos ejércitos "que envolverán sus torsos / en todas las praderas del continente"; y un año más tarde, en la revista Ultra de Madrid (20 de febrero de 1921), publica un poema titulado "Gesta maximalista" (los "maximalistas", conviene no olvidarlo, eran los "bolcheviques"), cuyo sólo título ahorra explicaciones. (Para este aspecto de la producción poética de Borges puede verse Guillermo de Torre: "Para la prehistoria ultraísta de Borges", en Al pie de las letras, Buenos Aires: Ed. Losada, 1967, pp. 171-185; Carlos Meneses: Poesía juvenil de J.L. Borges, Barcelona: José Olañeta Editor, 1978). 
años puede mostrar que existen condiciones, tanto de índole subjetiva como objetiva, que legitiman y explican el surgimiento de un vasto aunque difuso movimiento renovador de postguerra, y que éste alcanza un espectro tan amplio que afecta todos los niveles de la vida social, aunque probablemente sea más visible en lo político y en lo cultural.

El carácter internacional tanto de esta crisis como del espíritu de cuestionamiento y renovación que fermenta en amplios sectores -una de cuyas manifestaciones, en el plano artístico, está constituida por las llamadas tendencias de vanguardia-explican el ámbito también internacional en que se despliegan las experiencias vanguardistas artísticoliterarias.

Si se toman en consideración estos factores, es perfectamente valedero el sustentar la pertinencia y legalidad histórica de un Vanguardismo hispanoamericano, que puede ponerse en correspondencia, como una variable específica, con un fenómeno internacional más amplio.

Las maneras como este impulso general contestatario y renovador se manifiesta dentro del conjunto de la producción literaria posterior al Modernismo necesitan ser estudiadas en concreto y puestas en relación con las condiciones propias en que nuestras sociedades viven la crisis y los cambios generales de los inicios del mundo contemporáneo. Más específicamente, habría que considerar que las tendencias de vanguardia que surgen en la literatura hispanoamericana de esos años forman parte de un proceso más amplio de renovación artística con respecto al Modernismo y sus epígonos, dentro de la cual representan los impulsos de ruptura más agresivos y experimentales que ésta lleva en su seno.

La puesta en relación de estas manifestaciones vanguardistas con su contexto - tanto el de la coyuntura histórica en que surgen como el de la tradición estética que enfrentan - puede permitir no sólo una caracterización más rigurosa de la fisonomía de conjunto de la literatura posterior al Modernismo, sino también una valoración adecuada de su función histórica en el desarrollo cultural del continente.

En la esfera de la producción literaria, el período que se abre a partir de la Primera Guerra Mundial, desde la perspectiva de los nuevos autores que se incorporan a las letras está marcado por una búsqueda renovadora de amplio espectro, en la cual se manifiesta la necesidad de superar las limitaciones de un Modernismo cada vez más retorizado.

El tratar de puntualizar así la cronología no significa desconocer el hecho de que con anterioridad a esta fecha se pueden encontrar una serie 
de manifestaciones en este mismo sentido; sólo que es difícil considerarlas como algo más que hechos aislados, anticipaciones si se quiere, pero que por lo mismo no logran imponerse como una tendencia discernible dentro del conjunto dominante. Sólo a partir de la guerra - y no está de más recordar que la muerte de Darío ocurre en 1916- esta nueva actitud poética comienza a perfilarse como un proceso generalizado de las nuevas promociones de escritores, quienes entran en conflicto polémico con los epígonos de Modernismo literario e impulsan una renovación y búsqueda de nuevos rumbos.

Aunque son evidentes las dificultades para precisar límites cronológicos estrictos en los hechos históricos-literarios -y por cierto la periodización literaria tampoco pretende ni requiere delimitaciones estrictamente puntuales--, es posible advertir ya en los años anteriores a la guerra del 14 una declinación del Modernismo como sensibilidad poética dominante. En estos años, por otra parte, en el propio interior del Modernismo surgen voces de cuestionamiento implícito o explícito ${ }^{9}$, destacando entre estas últimas el olímpico ademán del soneto de Enrique González Martínez: "Tuércele el cuello al cisne de engañoso plumaje...", incluido en su libro Senderos ocultos de 1911. Pero solamente después de los años de la guerra estas manifestaciones aisladas empiezan a catalizarse y van asumiendo el aspecto de una ruptura crítica y una renovación generalizada.

No es fácil llegar a una caracterización del conjunto de este período, ya que su fisonomía parece a primera vista no sólo compleja sino aun contradictoria, puesto que - como veremos más adelante - los impulsos de superación del Modernismo no se encauzan por una sola vía. En la producción literaria de este período postmodernista ${ }^{10}$ se encuentran tanto las obras del llamado Mundonovismo regionalista y rural como las más agresivas creaciones de un vanguardismo urbano y cosmopolita. Como ya se ha dicho, la renovación que en esos años surge presenta una gama muy amplia y difusa que amerita un examen menos deductivo que el que hasta ahora la ha enfocado.

\footnotetext{
9 Puede recordarse el revuelo que provocan algunos de los poemas de Lunario sentimental (1909) de Leopoldo Lugones -uno de los cuales precisamente se titula "A Rubén Darío y otros cómplices"-, en los que, sin romper en conjunto con el lenguaje sonoro del Modernismo, figuran metáforas que anticipan las preferencias posteriores ("...la luna repleta,/ se puso con gorda majestad de ganso ( a tiro de escopeta") o expresiones que firmaría un Futurista ("en versátil aerostación de ideas").

10 Federico de Onís, que parece ser uno de los primeros en emplear la expresión para denominar un período literario (la primera edición de su Antología de la poesía española e hispanoamericana es de 1934; hay una edición más reciente en New York, Las Américas Publ., 1961), se refiere con este nombre a la poesía de 1905-1914, en la que él observa "una
} 
Explicar, por otra parte, el surgimiento de una renovación como ésta en función del "agotamiento" de las formas del Modernismo es apenas dar cuenta de un aspecto fenoménico de su nacimiento: el rechazo - frontal o elíptico- a un lenguaje y una temática retorizados. No es su aspecto de negatividad lo que define realmente una renovación sino las propuestas positivas que contiene $\mathrm{y}$ busca imponer. $\mathrm{Y}$ este aspecto no puede ser comprendido a cabalidad sino en función de las condiciones históricas que determinan tanto el agotamiento de un código anterior como las modalidades de configuración del proyecto de reemplazo.

Por eso, las búsquedas renovadoras de las jóvenes promociones de postguerra están comprendidas en un proceso global de reajuste ideológico-cultural que entonces exigen las nuevas condiciones históricas. $\mathrm{Y}$ es esto lo que puede explicar tanto las limitaciones que encuentra en el código Modernista la nueva sensibilidad en fermento, como las orientaciones y características que el nuevo proyecto renovador adquiere y que van a diseñar la fisonomía de conjunto de ese período.

En último término, de lo que se trata es de "leer" las manifestaciones renovadoras -entre ellas las de vanguardia- como síntoma de un reajuste más general que tiene sus raíces últimas en el surgimiento de las nuevas condiciones históricas que marcan la contemporaneidad latinoamericana.

Los inicios de la época contemporánea, como se dijo anteriormente, ofrecen un hito de referencia cronológica en la Primera Guerra Mundial. Esto es válido también para nuestro continente, puesto que el conflicto bélico que entre 1914-1918 afecta al mundo tuvo para América Latina consecuencias que inciden profundamente en la evolución de su historia común. Entre éstas tiene particular relevancia la que se traduce en el desplazamiento de su eje de inserción al sistema económico mundial, proceso mediante el cual pasa a integrarse al área hegemónica de los

reacción conservadora, en primer lugar, del modernismo mismo, que se hace habitual y retórico como toda revolución triunfante, y restauradora de todo lo que en el ardor de la lucha la naciente revolución (modernista) negó". El período siguiente, que es al que nos referimos y donde con mayor propiedad puede encontrarse una búsqueda de superación, es el que Onís llama "ultramodernismo" (1914-1932). Tengo conciencia de la posible confusión a que pueda prestarse el hablar de una literatura post-modernista para referirse a toda la producción literaria nueva de la postguerra, ya que el uso tradicional tiende a limitar la aplicación del término a sólo una parte de ella (la literatura Mundonovista o criollista). Como no es la única irreverencia con los criterios tradicionales que se comete en este trabajo, es oportuno advertir que lo que se pretende es contribuir a una revisión crítica no sólo de algunas denominaciones (punto de menor importancia) sino de los criterios ideológicos que alimentan la historiografia literaria dominante. 
Estados Unidos de Norteamérica "1, lo que va a significar que el conjunto de nuestros países comienza a enfrentarse a un elemento común y homogéneo que actúa sobre su desarrollo y lo subordina. Este elemento, que es uno de los factores determinantes de nuestra evolución histórica en este siglo, está representado por la acción de los monopolios norteamericanos, los que al actuar con el respaldo político e incluso militar de su gobierno configuran el sistema expandente del imperialismo.

Por lo anterior se puede decir que el proceso histórico global de América Latina entra en una etapa de acentuación de su comunidad histórica, etapa que se caracteriza por las respuestas que sus diversos países desarrollan ante una condicionante común. Esto es lo que permite comprender el carácter relativo que comienzan a tener las diversidades nacionales y regionales, en un continente que progresivamente va pasando a depender de las mismas determinantes básicas, en la medida en que sus economías y su vida política y social ingresan al sistema hegemónico de los Estados Unidos.

Esta comunidad de condición histórica; conjugada con la diversidad del desarrollo nacional y regional alcanzado hasta ese momento, es un factor de fundamental importancia para comprender la sintaxis del proceso histórico latinoamericano de este siglo.

Otra de las consecuencias internas que acarreó la guerra para los países latinoamericanos fue que, dada la crisis en el comercio exterior que ésta provoca, se incentivara en muchos de ellos un proceso de sustitución de importaciones. Esta crisis y este proceso tienen una doble consecuencia en el plano socioeconómico: por una parte, se fortalecen los sectores más dinámicos, en especial las burguesías locales, con el crecimiento consecuente de las capas medias urbanas y el proletariado; por la otra, se debilita el poder económico de las oligarquías agrarias - por el receso de las exportaciones-y por ende su influencia política.

11 Esto tampoco puede comprenderse como un hecho repentino sino como un proceso gradual que entra en una etapa decisiva en función de la coyuntura de la guerra. Ya antes (y esto es tema con abundante bibliografía) se había iniciado la penetración económica norteamericana en el continente, pero se veia frenada en gran medida por la influencia de las potencias europeas; desde antes también se había manifestado la tendencia a darle fisonomía de principios (la doctrina Monroe) y hasta una forma institucional (todavia tímidamente esbozada en la Conferencia Panamericana de 1890). Pero el llamado "Panamericanismo" (contrapartida imperial del hispano o latinoamericanismo bolivariano) no asume su dimensión omnímoda y dominante sino a partir de la superación de la crisis económica de 1907-1908 y del cambio en la correlación internacional que acarrea la guerra, momento que puede precisarse con la celebración del Primer Congreso Financiero Panamericano de 1915 en Washington. Por otra parte, las potencias europeas, que ven amagada su hegemonía a partir de esta misma guerra, tampoco dejan de intervenir y de participar en las economías y la vida política latinoamericanas. Incluso propician varios intentos para recuperar por lo menos parte de su control, pese a lo cual gradualmente terminan por convertirse, en términos generales, en factores subsidiarios y de influencia reducida con respecto a los Estados Unidos. 
El proceso de sustitución de importaciones, que en cierto modo estimula la producción nacional y el crecimiento de los asi llamados sectores secundario y terciario de la economía, se traduce en el plano de la vida social en un marcado crecimiento urbano - sobre todo en las capitales de estado $^{12}$-, y en un incremento cuantitativo del proletariado urbano y de las capas medias, especialmente las relacionadas con el sector de servicios $^{13}$.

Como consecuencia también de las alteraciones económicas y sociales de esos años, "las nuevas clases medias y ciertos sectores populares - apunta J. L. Romero- comenzaron a organizarse políticamente y a reclamar su derecho a intervenir en la vida política del país. $O$ en el seno de los viejos partidos o a través de partidos que trataban de constituirse, estas nuevas masas urbanas empezaron a exigir que se hiciera efectiva la democracia" 14 .

El fortalecimiento de nuevos sectores económicos, el crecimiento y concentración urbanos, la incorporación a la escena política de estos sectores medios y populares, unido al crecimiento y consolidación orgánica del proletariado, son hechos de gran importancia en la transformación de la vida política, social y cultural que se desarrolla en esos años.

Todo esto hace patente y agudiza el paulatino desplazamiento de los valores rurales y oligárquicos que dominaban en una formación anterior predominantemente agraria, resquebrajándose así la superestructura

12 Sobre esto puede verse el libro de José Luis Romero, Latinoamérica: las ciudades y las ideas (México: Siglo XXI Editores, 1976), esp. pp. 247 y ss.; además Walter D. Harris, El crecimiento de las ciudades en América Latina (Buenos Aires: Ediciones Marymar, 1975), Phillip M. Hauser, La urbanización en América Latina (Buenos Aires: Solar / Hachette, 1967), Varios, Urbanización y proceso social en América (Lima: Instituto de Estudios Peruanos, 1972), esp. Harley L. Browning, "Primacy Variations in Latin America during the Twentieth Century" (pp. 55-77) y Marcos Kaplan, "La ciudad latinoamericana como factor de transmisión de poder socioeconómico y político hacia el exterior durante el perfodo contemporáneo" (pp. 219-256).

13 Sobre las capas medias (que a menudo son confundidas e integradas en un mismo rango categorial con la "pequeña burguesía" por la actual ideología sociologista) se encuentra abundante -y heterogéneo- material en la compilación de Teo Crevena, Materiales para el estudio de la clase media en América Latina (Washington: Unión Panamericana, 1950-1951, 6 volúmenes). Para el estudio del desarrollo del proletariado urbano es útil el libro de Carlos $\mathbf{M}$. Rama, Historia del movimiento obrero y social latinoamericano contemporáneo (Barcelona: Editorial Laia, 1976), esp. el Cap. IV: "Los movimientos sociales de América Latina de 1900 a 1961" (p. 70-95). Una discusión sobre el origen, carácter y función de las clases en América Latina se encuentra en la recopilación de trabajos de B. Kovar y otros, Estructura clasista de América Latina (Bogotá: Ediciones Suramérica, 1975); acerca del carácter y el papel que juegan las distintas clases y capas sociales en el continente puede verse el capítulo "Zur Klassenstruktur in den kapitalistischen Ländern Lateinamerikas", pp. 43 a 121 del libro de M. Uschner (ed.), Lateinamerika: Schauplatz revolutionärer Kämpfe (Berlin: Staatsverlag der DDR, 1975).

14 José Luis Romero, op. cit. supra, p. 292. 
ideológica que amalgamaba las sociedades, con lo cual se abre un verdadero período de cuestionamiento y crisis en este plano.

Lo que sucede es que el marco de relaciones determinado por un tipo de producción fundamentado en la gran propiedad rural se hace estrecho para el desarrollo de las nuevas fuerzas económicas que históricamente buscaban imponerse. La necesidad de liberación de mano de obra, la centralización política en un Estado proteccionista, el imperioso crecimiento bancario ligado a las necesidades del comercio y la industria, las nuevas funciones del Estado al servicio de estas necesidades (como la modernización de vías de comunicación y sistemas de correos y telégrafos), etc., todo hacía imprescindible romper la anquilosada organización institucional originada en condiciones distintas a las que ahora surgían.

Esta situación es la que permite explicar el hecho de que prácticamente en todos los países de América Latina surjan movimientos antioloigárquicos y reformistas, que en casi todos ellos se fortalezca una "oposisión antioligárquica" policlasista y que una ola de populismo (a menudo honestamente inspirado, pero con frecuencia también demagógico) caracterice la vida política de ese momento y hasta el inicio de los años 30 .

Es posible, por lo anteriormente visto, establecer que el período que se extiende desde la Primera Guerra Mundial hasta la crisis económica internacional de 1929, si en lo económico está signado por la integración al expandente sistema imperialista norteamericano, y en lo social por el crecimiento de la burguesía urbana, de las capas medias y el proletariado y sus organizaciones, se caracteriza en lo politico por el auge de los movimientos antioligárquicos y populares, y por la incorporación activa en estas luchas de las capas medias y del proletariado.

Los componentes sociales de esta que hemos llamado "oposición antioligárquica" (burguesía y capas medias, con participación y presión de sectores populares) hacen que su tónica programática - por lo menos en los momentos de ascenso iniciales - sea antioligárquica y antimperialista, y adquiera un carácter de masas en un grado hasta entonces nunca visto ${ }^{15}$.

En el plano de la vida cultural, tal vez el acontecimiento que mejor pueda ilustrar esta nueva situación que va forjándose en la América Latina de la primera postguerra es el de la Reforma Universitaria.

Este movimiento, que se inicia en 1918 en Córdoba (Argentina), en opinión de José Carlos Mariátegui, "se presenta íntimamente conectado

15 En este proceso de conjunto habría que insertar hechos como el triunfo del candidato radical Hipólito Irigoyen en 1916 en Argentina, el triunfo de la Alianza Liberal con Arturo Alessandri en 1920 en Chile, el triunfo de Augusto B. Leguía en 1919 en Perú, el derrocamiento de la dictadura de Manuel Estrada Cabrera en 1920 en Guatemala, la llamada “revolución juliana" de los militares jóvenes en Ecuador en 1925, etc. 
con la recia marejada post-bélica", y en él se confirma la existencia de una condición común y compartida en casi todos los países del continente. Como observa el mismo Mariátegui, "el proceso de agitación universitaria en la Argentina, el Uruguay, Chile, Perú, etc., acusa el mismo origen y el mismo impulso. La chispa de la agitación es casi siempre un incidente secundario; pero la fuerza que la propaga y la dirige viene de ese estado de ánimo, de esa corriente de ideas que se designa - no sin riesgo de equívoco- con el nombre de 'nuevo espíritu'. Por esto, este anhelo de la Reforma se presenta, con idénticos caracteres, en todas las universidades latinoamericanas. Los estudiantes de toda la América Latina, aunque movidos a la lucha por protestas peculiares de su propia vida, parecen hablar un mismo lenguaje" 16 . "Tan hondo es el significado y tan grande es la idea - afirma otro autor-, que ella se extiende pronto por toda América Latina (...): primero fue Córdoba, después Buenos Aires, Santa Fe (1919), La Plata (1919-1920), Tucumán (1921), Cuzco y Santiago de Chile en 1920; México (1921), y más tarde Montevideo, La Habana, Bogotá, Trujillo, Quito, Guayaquil, Panamá, La Paz, Asunción..." 17.

El movimiento de la Reforma Universitaria en América Latina no se planteaba una simple modernización de los programas y métodos de la docencia; fue un movimiento de carácter integral que buscaba imponer una nueva concepción de la cultura y la enseñanza en función de los intereses populares, las necesidades nacionales y la transformación social. Fue básicamente antioligárquico y antimperialista, y a través de él se encauzó lo más radical y avanzado del movimiento popular que se veía mediatizado por la burguesía una vez que ésta asumía posiciones de gobierno.

Lo que Mariátegui describe como proceso de "proletarización de las clases medias" a consecuencias de la crisis de postguerra, impulsa a los sectores estudiantiles (provenientes en su gran mayoría precisamente de estas capas sociales) a buscar una alianza con los trabajadores, radicalizando así sus propios planteamientos, con el fin de imponer reformas sociales, políticas y económicas que las clases dirigentes vacilaban aceptar.

Esta situación y el destino de la Reforma Universitaria, como asímismo el de algunos de sus líderes y propulsores, puede ilustrar bastante bien

16 José Carlos Mariátegui, Siete ensayos de interpretación de la realidad peruana (1928) (Lima: Empresa Editora Amauta, 1975, p. 122). La mejor publicación de conjunto que conocemos sobre este proceso son los tres volúmenes de Gabriel del Mazo (comp) La Reforma Universitaria (La Plata: Edición del Centro de Estudiantes de Ingenieria, 1941. Tomo I: El movimiento argentino; tomo II: Propagación americana; tomo III: Ensayos críticos).

17 Noel H. Sbarra, "La Reforma Universitaria: evocación y presencia" (1928), reproducido en la ya citada obra de Gabriel del Mazo, tomo III, p. 457-458. 
tanto el sistema interno de contradicciones sociales que existía en la "oposición antioligárquica" como las consecuencias que tuvo en el desarrollo posterior de las sociedades del continente.

A partir de este ejemplo, si se toma en cuenta el complejo sistema de intereses subyacentes en las manifestaciones políticas y culturales de esa etapa de postguerra, es posible comprender el por qué, sobre todo en su momento de ascenso, el desarrollo de la renovación artístico-literaria del continente ofrece un panorama tan abigarrado, tan complejo y contradictorio. Independientemente del grado de conciencia real que pudieran alcanzar sus protagonistas, es legítimo sostener que esta etapa de renovación, cuestionamiento y búsqueda en el plano de la producción literaria se encuentra vinculada al proceso de transformaciones y cambios por el que atraviesa el conjunto de la sociedad latinoamericana de la postguerra.

Este proceso de transformación, que alimenta un impulso de cuestionamiento crítico y renovador, se extiende por todo el decenio de los años 20. Hacia 1930 es liquidado institucionalmente en la mayor parte de América Latina al consolidarse una alianza política entre los intereses económicos del imperialismo, las burguesías locales y las oligarquías, que, en defensa del sistema afectado por la crisis del 29 , recurren al golpe militar y a la represión para consolidar su dominio ${ }^{18}$.

Del mismo modo que la crisis provocada por la Primera Guerra Mundial había alimentado y creado la coyuntura para el avance de fuerzas renovadoras y reformistas, la crisis económica internacional de 1929 repercute en todo el continente, clausurando una etapa inicial de la contemporaneidad y abriendo una nueva.

\section{III}

Este cambio en la situación histórica global, como ya hemos dicho, se traduce en el plano de la producción literaria por el fin de la vigencia del

18 Es interesante registrar aquí la observación que hace un historiador francés en un reciente libro: "Evidentemente la gran crisis económica iniciada en 1929 en New York y la baja brutal de las exportaciones de América Latina tuvieron graves consecuencias políticas en un gran número de países de América. Es por lo mismo sorprendente que los golpes de estado, sublevaciones y conflictos diversos de los años 1929-30 no hayan sido estudiados -o lo hayan sido apenas-- desde esta perspectiva" (François Chevalier) L'Amérique Latine de l'indépendence à nos jours. Paris: P.U.F., 1977, p. 463). Esta nueva etapa que desencadena la crisis mundial del 29 se caracteriza por las dictaduras militares que se generalizan hasta tal punto que un historiador conservador, José Belmonte, puede constatar que "en vísperas de la segunda guerra mundial todos los países de Iberoamérica, a excepción de cuatro, tenían gobiernos militares (Historia contemporánea de Iberoamérica, Madrid: Guadarrama, 1971, tomo 1, p. 40 ). 
Modernismo como código dominante y el surgimiento de una compleja serie de impulsos renovadores de diverso alcance.

Un examen del conjunto de la producción literaria de la primera etapa post-modernista, la que va aproximadamente de 1918 a 1930, nos muestra que paralelamente a las tendencias que se han llamado nativistas, regionalistas, criollistas o mundonovistas, aparecen y se desarrollan las variadas manifestaciones polémicas y experimentales de lo que se conoce como Vanguardismo artístico. Pero este mismo examen nos mostraría que estas dos tendencias no logran compartimentar la totalidad de la literatura que entonces se da (pensemos, a mero título de ejemplo, en la obra de Roberto Arlt, Felisberto Hernández, José Gorostiza, etc.), por lo que más que agotar el panorama de conjunto pueden ser consideradas como los polos extremos entre los cuales se despliega el amplio abanico de la renovación artística.

Por eso mismo, parece más ajustado a la realidad el definir esta etapa post-modernista en Hispanoamérica como un proceso renovador de amplio espectro, cuyos cauces más definidos se pueden determinar por tendencias a primera vista polarizadas, pero que no hacen sino establecer los límites dentro de los cuales se mueve una variedad concreta de manifestaciones cuya taxonomía no es fácil de elaborar. Estas dos polaridades serían el criollismo o mundonovismo, por una parte, y los diversos brotes vanguardistas por la otra. Entre ambos polos, ora aproximándose a uno ora al otro, oscila y se concreta la producción literaria de la primera postguerra.

La primera de estas tendencias no implica en su renovación una ruptura plana y un rechazo directo del Modernismo, sino más bien un rechazo parcial y la búsqueda de profundización y desarrollo de uno de sus aspectos. Porque más allá de una visión manualesca de este movimiento, habrá que reconocer que no todo él se reduce a búsquedas estetizantes, simbolismo elitesco, cosmopolitismo y torre de marfil. No debe olvidarse que en el mismo Azul (1888) de Rubén Darío, que es todo un símbolo del movimiento, se encuentra un relato como "El fardo", en el que los lancheros de Valparaíso desequilibran el mundo de princesas, ninfas y gnomos. Y que un escritor estrictamente coetáneo de Darío, el chileno Baldomero Lillo (ambos nacen en 1867), jerarquiza a la inversa la misma temática Modernista, ya que si bien en su obra más difundida, Sub Terra (1904), el universo poético lo pueblan los mineros del carbón, en el volumen de intención simétrica, Sub Sole (1907), no escatima los palacios, las princesas y las flores. Habría que tener presente que en el crisol del Modernismo no sólo se produce la fusión del simbolismo y el parnasianismo, sino también del naturalismo. Y gran parte de su 
producción no podría comprenderse a cabalidad sin esta filiación. Es este aspecto del Modernismo lo que ha llevado a que algunos estudiosos, como Arturo Uslar Pietri, distingan un "modernismo criollista" dentro de ese conjunto $^{19}$. Esta misma razón es la que en cierto modo subyace en la distinción de las "dos etapas" del Modernismo que postula Max Henríquez Ureña ${ }^{20}$.

A partir del reconocimiento de este aspecto de la producción Modernista, no es difícil comprender que se puedan encontrar en él las raíces de una de las tendencias que desarrolla la literatura inmediatamente posterior, aquella que acentúa la preocupación por la realidad nacional especialmente en sus aspectos rurales, y que Francisco Contreras denominara con el término "Mundonovismo" 21.

La otra tendencia que polariza el conjunto de la literatura de postguerra se relaciona con el espíritu y desarrollo internacional de las tendencias vanguardistas, y está representada por las diversas manifestaciones polémicas del Vanguardismo hispanoamericano. En ella se encauza una línea nueva y agresiva de ruptura, prodigada en revistas, manifiestos y otras publicaciones a menudo efímeras y de escasa circulación. No siempre la actidud manifiesta de esta vanguardia es consonante con su producción concreta, pero en todo caso busca definirse por su actidud polémica y de radical ruptura con la tradición, representada en este caso por los Modernistas y sus epígonos. Y si la polaridad Mundonovista orienta sus preferencias temáticas hacia los ambientes rurales y busca por medio del lenguaje "objetivar" la perspectiva de la enunciación poética, la polaridad Vanguardista se caracteriza por su preferencia por los motivos urbanos y el buceo en la subjetividad.

19 Cf. Breve historia de la novela hispanoamericana (Caracas - Madrid: Edime, 2a. ed., 1974, p. 91 y ss). Como observa Julio Planchart, también a veces se usó "modernismo" como sinónimo de "criollismo" (Cf. Temas críticos, Caracas: Ediciones del Ministerio de Educación Nacional, 1948, pp. 10-11 y p. 431).

20 Cf. Breve historia del modernismo (México: Fondo de Cultura Económica, 1954), pp. 3132.

21 Francisco Contreras emplea al parecer por primera vez el término en una nota para el Mercure de France (16 de febrero de 1917). Posterioremente la va ampliando para referirse sobre todo a la obra de poetas que se apartan de las normas del Modernismo canónico, como Enrique González Martínez, Manuel Magallanes Moure, Baldomero Fernández Moreno, José Eguren. En el "Premio" a El pueblo maravilloso (Paris: Agencia Mundial de Libreria , 1927) lo define así: "El actual movimiento de nuestras letras, el Mundonovismo (Nota de F.C.: Otros llaman a este movimiento Americanista), que en pos de asimilarse las verdaderas conquistas del Modernismo, aspira a crear una literatura autónoma y genuina, busca instintivamente su inspiración en nuestro tesoro tradicional y característico, a partir de reflejar las grandes sugestiones de la tierra, de la raza, del ambiente" (subrayado por N.O.T.). El texto completo de "Proemio" puede consultarse en José Promis, Testimonios y documentos de la literatura chilena (1842-1975). Santiago de Chile: Nascimento, 1977, pp. 233-240. 
Pero estas dos tendencias así esquematizadas, como se ha dicho, no representan sino dos extremos de un conjunto abigarrado y plural, cuyo espectro permite situar entre una y otra polaridad las manifestaciones concretas de la producción literaria de ese período. Porque resulta difícil reducir estrictamente a una de ellas la obra renovadora que realizan en esos años, por ejemplo, César Vallejo o Roberto Arlt, Fernando Paz Castillo, León de Greiff, Felisberto Hernández, Julio Garmendia, José Gorostiza, Arturo Uslar Pietri, Jorge Carrera Andrade, etcétera ${ }^{22}$.

Por el mismo hecho de tratarse de abstracciones teóricas y metodológicas, no tiene tampoco sentido tratar de adscribir estrictamente a una u otra tendencia todas y cada una de las obras que entonces se escriben, ya que la misma contemporaneidad y la comunidad de circunstancias históricas hacen que haya una contaminación recíproca, por lo que en la producción concreta estas tendencias deben considerarse más como una jerarquización de preferencias que como exclusiones irreductibles.

Por ello, para lograr una comprensión más integral del conjunto de la producción literaria hispanoamericana de este período, se hace necesario reconocer la condición jánica de su fisonomía histórica. En ella, si bien una de sus caras representa la solución de continuidad en la superación renovadora del Modernismo, la otra, en actitud de proclamada ruptura, anticipa embrionariamente un proyecto que mucho más tarde va a desembocar en la literatura de los años sesenta.

Tal vez esta misma condición es lo que explica el que la historiografía tradicional - sobre todo la que se impone a partir del proceso de restauración que en lo político se manifiesta después de la crisis del 2930-, atraída por lo que estaba más próximo temática y lingüísticamente a los gustos dominantes, haya peraltado la producción regionalista y a partir de ella se haya definido el conjunto, relegando a un ámbito marginal o subterráno la producción que no se ajustaba a dichos cánones, hasta el punto que la denominación Post-Modernismo ha venido a ser casi sinónimo de literatura regionalista o criollista. Pero el descuido en que se ha mantenido el estudio de la producción literaria más ligada al vanguardismo no empece el que tenga una robusta existencia, y en la actualidad, particularmente por el auge que ha tenido la llamada "nueva narrativa", de los años 60 , se hace cada vez más necesario el conocerla y reconocer la importancia fertilizadora que tiene para la evolución de las letras hispanoamericanas.

\footnotetext{
22 Nuestro colega Raúl Bueno Chávez nos ha puesto en contacto con la obra de Alejandro Peralta, cuyo libro Ande (1926) -en el que los motivos indigenistas y rurales se poetizan en un lenguaje agresivamente vanguardista - puede ser un buen argumento contra cualquier intento de polarización maniquea.
} 
Esto último, también es verdad, no podrá apreciarse en su verdadera dimensión mientras no se amplíen las investigaciones sobre este aspecto "vanguardista" del período Post-Modernista. Y sobre todo, mientras se continúe considerando implícitamente el Vanguardismo hispanoamericano como un hecho postizo, como un simple epifenómeno de los movimientos europeos, es decir, mientras sólo se consideren como "vanguardistas" aquellas manifestaciones que se correspondan con los "ismos" europeos de la época. Esta perspectiva hace que se pierda la posibilidad de ver lo que hay de hispanoamericano en nuestro Vanguardismo y sólo se pueda dar cuenta de lo que tenga de europeo.

Por eso sostenemos que en el estudio del Vanguardismo en nuestra literatura de esos años estas tendencias no sólo deben considerarse en función de una legítima homología con respecto al conjunto de la vanguardia internacional, ligadas como están a un proceso de universalización de las condiciones históricas que influyen en su aparición, sino que se hace necesario también no perder de vista las peculiaridades y diferencias que le dan una fisonomía propia dentro del conjunto, como búsqueda de expresión de nuevos sectores emergentes y como búsqueda de respuesta a la nueva situación que se desarrolla en el continente sobre todo a partir de la postguerra.

\section{IV}

El dar paso a una perspectiva de estudio nueva y a una comprensión histórica más cabal del Vanguardismo y su función en nuestro proceso cultural, hace necesario reconsiderar y superar ciertas nociones heredadas que funcionan, a menudo implícitamente, en la historiografía tradicional cuando aborda el tema.

Probablemente una de las primeras cosas que habría que empezar por cuestionar es la arraigada práctica de caracterizar deductivamente esta tendencia en función de las escuelas canonizadas de las vanguardias europeas. Esto lleva a presumir de partida su condición de epifenómeno ${ }^{23}$, de manifestación ancilar, eco o reflejo de búsquedas que corresponden a otra realidad y a otras necesidades, todo lo cual lleva a considerar el Vanguardismo literario en el continente como producto ligeramente artificial de una moda impuesta, sin mayores vinculaciones con la realidad y las condiciones concretas en que se manifiesta.

23 "Los ismos que aparecieron -dice Anderson Imbert-- fueron sucursales de la gran planta industrial con sede en Europa" (Historia de la literatura hispanoamericana. México: Fondo de Cultura Económica, 5a. ed., 1966, tomo II, p. 16). 
Sin dejar de tomar en cuenta la influencia que ejercen y la importancia que tienen en muchos aspectos de la elaboración programática del Vanguardismo en nuestro medio, no es objetivo ni tiene fundamento científico el reducir lo que pueda considerarse vanguardismo en América Latina sólo a las manifestaciones estrictamente asimilables a las escuelas europeas. Porque si bien hay una comunidad de impulso y son comunes los sentimientos de crisis y de insurgencia antirretórica, las manifestaciones del vanguardismo hispanoamericano encuentran sus raíces ideológicas en un proceso propio de cuestionamiento crítico que se vincula al ascenso de nuevos sectores sociales en América Latina.

El carácter internacional que tiene el vanguardismo de la postguerra está relacionado con la internacionalización de una crisis que condujo a la guerra, pero el mundo hispanoamericano vive de un modo específico esta situación. En nuestro continente esta crisis pone de manifiesto la anquilosis de las estructuras de una sociedad oligárquica, las que entran en contradicción con las necesidades de expansión de las nuevas realidades y fuerzas sociales.

Como se puede desprender del examen de las condiciones históricas generales de la postguerra en América Latina, esta situación se traduce en el crecimiento de una oposición antioligárquica, alimentada por una gama muy amplia de sectores y fuerzas sociales, que abarca desde la burguesía industrial, mercantil y bancaria, hasta el creciente proletariado urbano.

El proceso de desplazamiento de las oligarquías tradicionales del poder se cumple como un reemplazo de sectores hegemónicos en el interior de las clases dominantes ${ }^{24}$. Sin embargo, a nivel de lo que se llama la superestructura social, hay un resquebrajamiento y un proceso de reajuste del sistema ideológico dominante $\mathrm{y}$ del aparato institucional que lo sustenta, lo que da lugar a un cuestionamiento crítico abigarrado y multiforme. En esta coyuntura, la misma pluralidad social e ideológica de la oposición antioligárquica explica la multiformidad de las tentativas críticas que surgen, $y$ en las que, si bien puede encontrarse - sobre todo en el primer decenio de postguerra- comunidad en la actitud cuestionadora, no hay coincidencia en las respuestas, que son variadas, multifacéticas y hasta contradictorias.

Este cuestionamiento del sistema de valores institucionalizados y tradicionales, en mayor o menor grado se proyectaba a todas las esferas de

24 Utilizando los términos de las categorías económicas, esto significa que se produce un cambio en el modo de producción social dominante, pero no un cambio en la relación con los medios de producción, que siguen siendo privados. Este proceso histórico es lo que -extendiendo la afirmación que Mariátegui hace para el Perú- - "en el plano político produjo la caída de la oligarquía representativa de la casta feudal a causa de su ineptitud para devenir clase capitalista" (Siete ensayos..., ed, cit., p. 118). 
la vida social, y un ejemplo de ello podemos verlo al examinar el carácter que adquiere la Reforma Universitaria que se inicia el 18. Pero en el terreno del arte y la literatura, especialmente en el período inmediatamente posterior a la guerra, se dirigía sobre todo a la superación crítica del Modernismo. La producción literaria de los epígonos del Modernismo devenía cada vez más retórica y su lenguaje y preferencias se sentían artificiales y ajenos a la nueva sensibilidad en formación. La necesidad de superarla se hace urgente, y aunque las nuevas promociones coinciden en asumir esa actitud de cancelación de un sistema y código literarios, no coinciden, sin embargo, programáticamente en las vías para lograrlo, lo que hace que la elaboración de respuestas se abra como un amplio abanico de búsquedas 25 .

Uno de los polos de esta búsqueda está constituido por el Vanguardismo hispanoamericano.

A partir de estos elementos, es posible comprender que el surgimiento de manifestaciones vanguardistas en la producción literaria del continente se vincula a condiciones objetivas de carácter social y cultural, y que el Vanguardismo hispanoamericano se relaciona al modo y las condiciones en que se vive la crisis internacional de la postguerra en esta parte del mundo. Por tales razones, para una compresión y caracterización más rigurosa del vanguardismo literario hispanoamericano, se hace necesario despejar sus nexos con las condiciones propias del continente, en particular con el desarrollo de nuevos sectores sociales urbanos -especialmente capas medias, intelectuales y estudiantes-, sectores que en lo político y social vivían activamente el proceso de cuestionamiento antioligárquico que marca la inmediata postguerra, con todas las ambigüedades, debilidades, contradicciones e inconsecuencias que ese mismo proceso tuvo.

Un estudio más ceñido podría mostrar los vínculos que existen entre las manifestaciones vanguardistas en nuestra literatura y la incorporación de estos nuevos sectores sociales urbanos al activismo crítico de la postguerra. Como una de las formas de expresión del espíritu crítico que llevan dichos sectores en su etapa ascendente, las manifestaciones de la Vanguardia hispanoamericana no sólo adquieren su legitimación histórica sino que

25 A riesgo de aparecer como sospechoso de herejía mecanicista, habría que llamar la atención sobre el hecho de que la misma unidad de cuestionamiento (oposición antioligárquica) y divergencia en la respuesta se puede observar en el movimiento político social que agita la vida de esos años. 
además muestran aspectos propios que no son fácilmente reductibles a los cánones del vanguardismo europeo ${ }^{26}$.

Hay otro aspecto importante que se hace necesario tomar en cuenta para un intento de caracterización del Vanguardismo hispanoamericano: la necesidad de intentar el examen de su producción considerándola como un conjunto continental y no sólo como una simple suma informativa de manifestaciones nacionales aisladas. Se trataría, en último término, de un diseño téorico del "espacio intelectual" configurado por la vanguardia, concebido como el sistema de relaciones en que están imbricadas cada una de sus realizaciones concretas. Para ello habría que establecer las correspondencias que, con o sin contacto directo, se pueden encontrar entre las manifestaciones grupales o individuales de distintos países, a fin de poder determinar un marco referencial en lo literario que permita una comprensión de las variables nacionales que adquiera un proceso que abarca todo el continente ${ }^{27}$.

Esto se hace tanto más necesario cuanto que hasta ahora cada una de las manifestaciones particulares se suelen estudiar poniéndolas directamente en relación con el vanguardismo europeo y no con un conjunto hispanoameri-

26 Por otra parte no estaría de más subrayar de paso la frecuencia con que los integrantes o impulsores de estas manifestaciones renovadoras de la vanguardia o del "arte nuevo" (que era la denominación con que la mayoría prefería identificarse) buscaron marcar su diferencia e incluso distanciamiento crítico con respecto a muchas de las tendencias del vanguardismo europeo. En un temprano texto de 1914, una de las figuras más destacadas de nuestra vanguardia, Vicente Huidobro, se refiere al Futurismo diciendo, entre otras cosas: "el señor Marinetti prefiere un automóvil a la pagana desnudez de una mujer. Es esta una cualidad de niño chico: el trencito ante todo. Agú, Marinetti. //En lo único que estoy de acuerdo con Marinetti es en la proclamación del verso libre" (Pasando y pasando. Santiago de Chile: Imprenta y Encuadernación Chile, 1914). Posteriormente, en sus Manifestes (Paris: Editions de la Revue Mondiale, 1925) vuelve sobre el tema y llama al Futurismo "un arte de nuevo aspecto pero nada fundamentalmente nuevo". En esta misma obra hace también una extensa crítica al Surrealismo ("Manifiesto de manifiestos"). Contra el Surrealismo se pronuncia también César Vallejo (Cf., v. gr., "Autopsia del Superrealismo", en Amauta, No 30, abrilmayo de 1930, pgs. 44-47). Una actidud más matizada, aunque también cautelosa, es la de Mariátegui en sus diversos artículos sobre las vanguardias europeas (La mayor parte recogidos en J.C.M.: El artista y su época. Lima: Empresa Editora Amauta, 3a. ed., 1973; otros en id.: Peruanicemos a Perú. Lima: Empresa Editora Amauta, 3a. ed., 1975). Parecida actitud de valoración crítica se puede advertir en los artículos sobre "Vanguardismo" y sobre el "Arte nuevo" de la Revista de Avance de la Habana (Cf. esp. Martín Casanova: "Arte nuevo", el 15 de junio de 1927). Puede decirse que, en general, se advierte entre los sostenedores del "arte nuevo" de los años 20 una actitud de valoración distanciada respecto a las vanguardias artísticas europeas, y la defensa que de ellas hacen contra los "pasatistas" no puede entenderse como una identificación ni como una adhesión incondicional.

27 Al subrayar en este punto la necesidad de considerar el carácter continental que tiene el vanguardismo no debe pensarse que lo consideremos una particularidad nueva. Es perfectamente claro que con anterioridad, especialmente en el Modernismo, también se dio la "continentalización" de un movimiento estético. Lo queremos es insistir en la existencia de este carácter para la vanguardia, por tratarse de un hecho no siempre valorado ni tomado suficientemente en cuenta. 
cano. Es indudable que el Vanguardismo de entreguerras es un fenómeno internacional, pero no es menos cierto que en nuestro medio el primer nivel de esta "internacionalidad" lo constituye el conjunto continental, y a él debieran ser referidos inicialmente los fenómenos locales. Una perspectiva como ésta no sólo posibilitaría una comprensión más plena de muchas obras y autores que se vinculan a esta tendencia -y que no estudiarlos así aparecen como hilos sueltos, casos raros y singulares, desintegrados del conjunto nacional ${ }^{28}$-, sino también posibilitaría comprender mejor el carácter y significación del Vanguardismo hispanoamericano como parte del perfil artístico de un período, y su función en el proceso evolutivo de nuestra vida cultural.

El principal obstáculo para este examen de conjunto reside en la arraigada tendencia historiográfica y crítica que lleva a considerar la literatura hispanoamericana no como una síntesis diferenciable, como un espacio propio, sino como una sumatoria mecánica de literaturas nacionales, cada una de las cuales obedece a un principio evolutivo inmanente $\mathrm{o}$, a lo más, a impulsos de índole estrictamente local ${ }^{29}$. Para superar este esquema ideológico es necesario considerar que en la medida en que los hechos económicos, sociales y políticos van unificando la condición histórica, se internacionalizan también sus manifestaciones superestructurales y la literatura, que es una de ellas, funciona también como fenómeno supranacional.

Ya el surgimiento mismo de la literatura vanguardista en Hispano América se nos presenta como una floración múltiple, puesto que aparecen brotes casi simultáneos en la mayoría de las ciudades importantes sin que exista un núcleo irradiador preciso o una concertación programática. Tendrá que ser tarea y responsabilidad de la crítica el poner en relación y organizar el sentido de esta presencia multiplicada que hasta ahora ha sido más bien vista, como fenómeno marginal, en un registro atomizado. El dilucidar el concierto implícito que surge de esta proliferación crea una perspectiva que permite el estudio de los brotes aislados ya no como "islas"

28 Piénsase, a título de ejemplo, en los casos de Hugo Mayo en Ecuador, José Antonio Ramos Sucre en Venezuela, Parra del Riego en Perú-Uruguay, Luis Vidales en Colombia, Juan Emar en Chile, etc.

29 Escapan en cierta medida a esta limitación algunas de las historias que se basan en el criterio generacional, como el Esquema generacional de las letras hispanoamericans de José Juan Arrom (Bogotá: Instituto Caro y Cuervo, 1963) y la Historia de la novela hispanoamericana de Cedomil Goió (Valparaíso: Ediciones Universitarias de Valparaíso, 1972). Sin embargo la pretendida solución se busca a través de otro esquematismo ideológico, ya que lo que se organiza no es la producción literaria sino a los autores, con lo cual se mediatiza y se distorsiona el objeto, incurriéndose en una deformación historiográfica que bajo apariencia de novedad reintroduce los viejos vicios del positivismo que se pretende superar. 
sino como parte de un verdadero "archipiélago" continental, como habitantes de un espacio propio y supranacional en el que entran en relación, dialogan y se jerarquizan.

En los hechos, los mismos escritores de la vanguardia sentían su quehacer funcionando en un espacio distinto al nacional, ya que si bien a ese nivel eran expresión de un proyecto minoritario no lo eran tanto en función de un impulso continental del que se sentían partícipes. En último término, conscientes o no de esta dimensión, a través de revistas y otras publicaciones mantuvieron un diálgo de afinidades que los enlaza como proyecto por sobre las fronteras.

El examen de algunas de las revistas de la vanguardia es revelador de esa consanguineidad continental $-\mathrm{y}$ universal- en la que se reconocían sus integrantes. Y si se piensa que la antología más importante del inicio de la poesía vanguardista, el Indice de la nueva poesía americana (1926, es preparada por el argentino Jorge Luis Borges, el peruano Alberto Hidalgo y el chileno Vicente Huidobro ${ }^{30}$, tendremos alguna idea del sentido que adquiría este espíritu. Por otra parte, el modo en que era enfrentado este problema puede ser ilustrado por uno de los comentarios a esta antología que se publica en Hangar, $\mathrm{N}^{\circ} 2$ :

por primera vez en un libro desde la civilización del hombre americano se cita todo el pensamiento del continente - destruyendo los límites creados por la fauna zoológica que infectó el orbe cuyo olor a cadaverina se siente en lugones - chocano - valencia - jaimes freire -etc- -etc- -etc- -etc- -etc- -etc-etc- -etc- -etc- -etc- -etc- aquí en américa todos somos americanos - la necedad de fronteras - un mito - no es cierto imbéciles patrioteros? ${ }^{31}$

En general, las publicaciones dentro de la órbita de la vanguardia en Hispano América, especialmente en su primera época tuvieron un marcado carácter supranacional, no sólo porque la composición de sus impulsores y colaboradores revela esta alimentación continental de sus páginas sino también por la índole de su proyecto e inquietudes ${ }^{32}$. Ejemplos paradigmáticos de esta orientación pueden considerarse las dos más trascendentes

30 Indice de la nueva poesía americana Prólogos de J.L. Borges, Vicente Huidobro y Alberto Hidalgo. (Buenos Aires: Sociedad de Publicaciones El Inca, 1926).

31 Hangar (ex-trampolín -arte supra-cosmopolita), No 2, Suramérica (2a. quincena de octubre, 1926). Se trata de una publicación que dirigieron Serafín Delmar y Magda Portal, y que tiene la particularidad de cambiar de nombre en cada número. Los cuatro que al parecer son los únicos que salieron son los siguientes: trampolin (revista supra- cosmopolita), hangar (ex-trampolín - arte supra-cosmopolita), rascacielos (ex-hangar - revista de arte internacional), timonel (ex-rascacielos). Las fechas correspondientes son octubre de 1926, 2a. quincena de octubre de 1926, noviembre de 1926 y marzo de 1927.

32 "MARTIN FIERRO cree en la importancia del aporte intelectual de América", señala el Manifiesto que redactara Oliverio Girondo para este grupo vanguardista argentino (Martín Fierro, I, 4 (15 de mayo de 1924). 
publicaciones periódicas de fines de ese decenio, la Revista de Avance (Cuba, 1927-1930 y Amauta (Perú, 1926-1930), editados en los extremos geográficos del continente.

Un examen, por somero que fuera, de la diversidad de manifestaciones de esta literatura de vanguardia, de este "arte nuevo" ${ }^{33}$, nos permitiría establecer una gran correspondencia y una profunda consanguineidad estética entre escritores de las más diversas latitudes del continente. Esto es particularmente llamativo en la etapa inicial, el momento más polémico y agresivo del vanguardismo, que alcanza hasta el final de los años 20. Esta consanguineidad hace que no sólo se reaccione contra los mismos valores sino que se haga casi en los mismos términos. No es extraño que, por ejemplo, en un artículo de 1924 Mariátegui critique el "pasadismo" de la literatura peruana de la época ${ }^{34}$ y que Jacinto Fombona Pachano califique al Modernismo de "pasatismo" 35; el término fue impuesto por los Futuristas italianos a partir del Manifiesto de 1910 de Marinetti "Contro Venezia passatista" 36 . Pero sí parece extraño y llama la atención un

33 Es importante insistir en la retiscencia de la mayor parte de los escritores y renovadores de este período para denominar su quehacer como "vanguardista", por lo menos antes de 1930. Hay algunas excepciones - como la revista Motocicleta de Hugo Mayo en Ecuador, que "aparece cada 360 horas" y se subtitula "Indice de poesía vanguardista"-, pero la mayoría prefiere referirse al "arte nuevo" (Revista de Avance) o a la "nueva sensibilidad" (los "martifierristas") o declararse llamados a "reivindicar el verdadero concepto del arte nuevo" (Revista Válvula, en Venezuela). También, por cierto, en esos años se fundan e inauguran ismos, lo que es, en cierto modo, otra manera de acentuar una búsqueda de fisonomía propia dentro de las tendencias conocidas del vanguardismo. De estos ismos el único que alcanza dimensiones históricamente considerables es el Creacionismo de Vicente Huidobro; pero hay muchos más, difíciles de pesquisar actualmente, ya que si bien algunos tienen importancia en el ámbito nacional, como el "Estridentismo" en México, otros son efímeros brotes, como el pintoresco "Runrunismo" en Chile, o el bipersolnal "Diepalsimo" (de José de Diego Padró y Luis Palés Matos) en Puerto Rico, o el "Simplismo" de Alberto Hidago; etc.

34 En su artículo "Pasadismo y futurismo", publicado en Mundial de Lima (31 de octubre de 1924).

35 En el artículo "Algunas críticas", publicado en Elite, I, 12, Caracas (5 de diciembre de 1925).

36 Veáse "Contro Venezia passatista", en la recopilación de Luciano de Maria Marinetti e il Futurismo (Arnoldo Mondadori Editore, 1973), p. 26 y ss. Otra expresión que también pusieron en circulación los Futuristas y que fue acogida por los vanguardistas hispanoamericanos fue la de "nueva sensibilidad". En su manifiesto del 11 de mayo de 1913, Marinetti habla de la sensibilidad futurista que "si fonda sul completo rinnovamento della sensibilità umana avvenuto per effetto delle grandi scoperte scientifiche", y luego en 17 puntos desarrolla "alcuni degli elementi della nuova sensibilità futurista". Entre los abundantes errores de la obra de Guillermo de Torre sobre las vanguardias uno de ellos es atribuir a Ortega y Gasset la paternidad de dicha expresión: "la expresión (...) nueva sensibilidad pertenece a Ortega y Gasset; fue tema o punto de partida de una de sus conferencias en Buenos Aires (1916) y sirvió luego para designar el nuevo estado de espíritu con mas frecuencia que los apelativos vanguardismo o ultraismo" (Historia de la literatura de vanguardia, ed. cit., p. 584). Sobre el concepto de "nueva sensibilidad" en el Futurismo puede verse el trabajo de Christa Baumgarth: Geschichte des Futurismus (Reinbeck/Hamburg: Rowohlt, 1966), esp. p. 130 y ss. 
ejemplo que nos muestra una reacción en los mismos términos en tres lugares diferentes, lo que hace pensar en una crítica similar generalizada. En el "Manifiesto de Martín Fierro" se declara que "MARTIN FIERRO sabe que 'todo es nuevo bajo el sol' si todo se mira con unas pupilas actuales y se expresa con un acento contemporáneo" ${ }^{37}$. Este "todo es nuevo bajo el sol" de los vanguardistas argentinos responde a la misma objeción que enfrentan los renovadores en La Habana: "Contra la pretensión de los jóvenes que clamamos por un arte nuevo, se opondrá siempre, con ademán poderosamente escéptico y peligrosa fuerza de simpatía, la vieja convicción de que nihil novum sub sole. ¿Cómo contestarla?" 38 . Y en esos mismos términos se expresan en la Caracas de 1928 los jóvenes que inauguran la primera revista vanguardista, válvula, donde se lee:

Sabemos que la rancia tradición ha de cerrar contra nosotros, y para el caso ya esgrime una de esas palabras suyas tan pegajosas: Nihil novum sub sole. Como luchadores honrados nos gusta conceder ventaja al enemigo; aceptemos a priori que no haya nada nuevo, en el sentido escolástico del vocablo, pero en cambio, y quien se atreverá a negarlo, hay mucha cosa virgen que la luz del sol no ha alumbrado aún. ¡Queda en pie la posibilidad del hallazgo! 39 .

Sin que sea necesario abundar en ejemplos, creemos que hay una indudable comunidad de actitud y de espíritu que enhebra el conjunto de las manifestaciones particulares de la vanguardia en Hispanoamérica y le da una cierta fisonomía unitaria y diferenciada. Por eso mismo, la caracterización y comprensión de cada una de sus realizaciones hace necesario que se tome en cuenta el conjunto al que se integran, ya que estas obras se sitúan más significativamente dentro de un espacio literario supranacional que en el sistema literario dominante en cada uno de los países en que surgen en esos años.

Parece importante agregar una tercera y última observación sobre los problemas de tipo teórico-metodológico que han entrabado y dificultado una caracterización más objetiva del Vanguardismo literario en el continente. Se trata de un lastre ideológico que es tanto más deformante cuanto que casi todos explícitamente lo dan por superado. Nos referimos a la división de la literatura en "géneros" 40.

37 Loc. cit. supra, nota 32

38 Jorge Mañach: "Vanguardismo. I", Revista de Avance. I, 1 (1927).

39 "Somos" (editorial de) válvula, I, 1 (enero de 1928). No parece excesivo recordar aquí el "Arte poética" de Huidobro (de El espejo de agua, 1916): "Sólo para nosotros / viven todas las cosas bajo el sol".

40 La originaria distinción que se hacía en la poesía en la Grecia antigua era fundamentalmente objetiva y funcional, ya que partía de los modos como se entregaba al receptor. La poesía hablada o recitada era la épica, la poesía cantada o musicada era la mélica 
En el caso concreto del período a que nos referimos, la historiografía tradicional, aquejada como se halla por esta taxonomía heredada, divide para su estudio a la literatura en poesía (poesía lírica), narrativa (novela, cuento) y teatro (literatura dramática). Pero en verdad ni siquiera se queda en esto, que ya es una deformación, sino que termina por clasificar no a la producción literaria sino a los autores en géneros. Con esto se produce una doble distorsión, ya que al encasillar a cada autor en un género (poeta, narrador o dramaturgo), además de aplicarse un criterio deductivo extrapolado de otras realidades culturales, se termina por no considerar de su obra sino aquello que corresponde al casillero en que se le encierra, relegándose a un segundo a tercer plano el resto de producción.

A partir de esta deformación metodológica se produce una más grave deformación de la imagen de conjunto de producción literaria. Sobre todo para el período a que nos referimos, los ejemplos son abundantes y graves en sus consecuencias histórico-literarias. César Vallejo, v. gr., ha sido encasillado en la poesía lírica; por consecuencia, su obra narrativa ${ }^{41}$ o no es tomada en cuenta o apenas si se la menciona subsidiariamente; y ni siquiera ha habido interés en examinar su producción dramática dispersa ${ }^{42}$. Por otra parte, como se le considera exclusivamente poeta (es decir, poeta lírico) y no cuentista o novelista, en los capítulos correspondientes dedicados a la narrativa de la época tampoco se le toma en cuenta.

o lírica, y la poesía representada era la dramática. Los cambios que históricamente se fueron introduciendo en los medios materiales de producción de obras literarias han alterado el fundamento de dicha distinción. El peso de una tradición hace sin embargo que actualmente se distinga entre poesia (lírica), novela/cuento (épica o narrativa) y teatro (dramática), sin que se pare mientes en que estas categorías obedecen ahora a criterios que habria que formalizar adecuadamente, y que por otra parte, no dejan de ser categorías abstractas, cuyas manifestaciones concretas no siempre son posibles de un deslinde riguroso. Para el caso específico de la literatura hispanoamericana, la aplicación mecánica de estas distinciones conlleva otros problemas que no pretendemos examinar aquí, pero que perturban seriamente los estudios, Nada más como ejemplo, piénsese en el modo como podría resolverse a partir de estos tres "géneros" casos como el de Los sirgueros de la Virgen de Bramón, o Los infortunios de Alonso Ramírez de Sigüenza y Góngora; y más próximamente obras como las Memorias de un venezolano de la decadencia de José Rafael Pocaterra o Confieso que he vivido de Pablo Neruda.

41 Piénsese en Escalas melografiadas (Lima: Talleres Gráficos de la Penitenciaría, 1923) o en Fabla salvaje (1a. ed. en La Novela Peruana, Año I, No, 9 Lima, 1923) o en El tungsteno (Madrid: Editores Cenit, 1931).

42 La producción dramática de Vallejo ha permanecido prácticamente inédita. Sin embargo Luis Monguió en la Bibliografía de su César Vallejo, vida y obra (Lima: Editora Perú Nuevo, 1952) menciona por lo menos 5 piezas dramáticas inéditas. En 1938, la revista Commune de París (VI, 60, 1938, pp. 1438-1441) publica una traducción parcial de Piedra cansada (como Pierre de soleil, tr. de Louis Parrot); en 1956 la revista Letras (Nos. 56-57, Lima, p. 5-18) publica Colacho hermanos, también parcialmente, Recientemente se editó en Lima un volumen con la obra dramática que no he podido consultar al escribir estas notas. 
Otro tanto es lo que sucede con Vicente Huidobro. Si se examina la última edición de sus Obras Completas (1976), de aproximadamente 1600 páginas de textos literarios poco más de 600 corresponden a su obra lírica en sentido estricto, y la mayor parte, excluyendo texto críticos y programáticos, es narrativa y dramática, hasta donde puedan seguir utilizándose elásticamente estas dominaciones. Este ejemplo, aun en su grosera dimensión cuantitativa, debería llamar la atención sobre el descuido deformante en que se mantiene - sobre todo para la caracterización del Vanguardismo literario hispanoamericano- una parte fundamental de la obra de uno de los escritores de mayor influencia en las letras de la época.

Como hasta ahora la historiografía tradicional, al referirse a las tendencias de vanguardia en nuestra literatura, ha tomado casi exclusivamente en cuenta la producción lírica, no es extraño que se observen fallas notables en la apreciación real de su fisonomía histórica.

Por eso, la necesidad de superar esta limitación de enfoque debe llevar necesariamente a una superación tanto de la taxonomía heredada de los "géneros" como de la historia literaria ordenada por autores ${ }^{43}$. Esto permitiría incluso en nuestro caso ajustarse más al espíritu mismo que impulsaban las vanguardias, que era de búsqueda creadora rompiendo moldes y casillas. Sólo así, además, dejarán de incomodar textos como Escalas melografiadas (1923) de César Vallejo, País blanco y negro (1929) de Rosamel del Valle, "E utreja" (1927) de Arturo Uslar Pietri, "Una historia extrañamente sentimental" (1925) de Jorge Zalamea, Mio Cid Campeador (1929) de Vicente Huidobro, las "novelas" de Macedonio Fernández, los "poemas" de José Antonio Ramos Sucre, etc., para sólo mencionar algunos casos de los años 20.

Un intento objetivo de establecer el carácter, aporte y significación del Vanguardismo literario de la primera postguerra no puede - no debe-, por otra parte, dejar de estudiar y valorar en esa dimensión obras como $E l$ habitante y su esperanza (1926) de Pablo Neruda, El Café de Nadie (1926) de Arqueles Vela, Sebastián Guenard (1925) de Isaac de Diego Padró, Escritura de Raimundo Contreras (1929, circula en el 44) de Pablo de Rokha, Margarita de niebla (1927) de Jaime Torres Bodet, La casa de cartón (1928) de Martín Adán, Novela como nube (1928) de Gilberto Owen, Dama de Corazones (1928) de Xavier Villaurrutia, etc.

43 Quienes vean como peligrosamente marxista o sociólogica esta proposición, pueden tranquilizarse recordando que lo primero fue planteado ya por Benedeto Croce, y que lo segundo era sostenido por Paul Valery en su Curso de 1937, donde llega a pensar que "una historia profundizada de la literatura (...) podría llegar a ser hecha sin que ni siquiera el nombre de un escritor fuera mencionado" (Cit. por ed. en castellano: Introducción a la poética, Buenos Aires: Rodolfo Alonso Editor, 1975, p. 10). 
A esta enumeración dispersa - referida exclusivamente a los años 20habría que añadir también la obra de escritores cuya producción total o parcial se alimenta de este mismo impulso renovador y antirretórico del Vanguardismo, como Pablo Palacio (Ecuador, 1906-1947), Julio Garmendia (Venezuela, 1898-1977), Juan Emar (Chile, 1893-1964), Eduardo Zalamea Borda (Colombia, 1907-1963), Enrique Bernardo Núnez (Venezuela, 1895-1964), etc.

Considerando un escueto y desprolijo muestreo como el anterior, es legítimo sospechar que un examen más detenido de la producción literaria real de la vanguardia no puede reducirse a la poesía lírica, y que el criterio mismo de organizar la literatura por géneros no contribuye a una comprensión adecuada del período. Por eso mismo, superar las limitaciones con que ha trabajado la historiografía vigente ha de significar necesariamente no sólo la posibilidad de tener una dimensión más plena del Vanguardismo hispanoamericano, sino también el poder valorar en un contexto más adecuado una serie de obras que aún siguen figurando - cuando figuran - como apéndices de excepción o casos singulares en la literatura de esos años.

Como puede desprenderse del somero examen que hemos tratado de realizar sobre las condiciones y el carácter de la producción vanguardista de la primera postguerra, nos enfrentamos a un aspecto extraordinariamente rico y descuidado de nuestra historia literaria. Aunque se han hecho algunos valiosos aportes sobre ciertos puntos específicos y sobre algunas obras y grupos literarios, las necesidades de una más adecuada valoración de los inicios de nuestra literatura contemporánea hacen cada vez más imperioso el emprender un examen de conjunto de este primer período del Vanguardismo hispanoamericano.

El descuido en que se ha mantenido y el superficial tratamiento que ha tenido en nuestra historiografía, sin embargo - y esta es otra conclusión que debería desprenderse del examen realizado-, no pueden atribuirse livianamente a desconocimiento o a falta de capacidad por parte de críticos e historiadores. Las fallas y debilidades que pueden apreciarse en el estudio de estas manifestaciones obedecen más bien a las limitaciones de la ideología historiográfica dominante que a deficiencias personales de sus usuarios. Por eso, una revisión de las características y las significación del Vanguardismo hace necesario que se superen al mismo tiempo algunas de las limitaciones más evidentes que plantea la historiografía literaria actual.

El dejar de considerarlo como un simple epifenómeno de las vanguardias europeas para tratar de comprenderlo como respuesta a condiciones históricas concretas, el superar el enfoque atomista de la literatura por 
países para visualizar su espacio continental, y el dejar de reducirlo a sus expresiones en la poesía lírica para incorporar la totalidad de sus manifestaciones son sólo algunas de las tareas de superación de un enfoque limitante que se hacen hoy día necesarias para una adecuada caracterización del Vanguardismo hispanoamericano.

Desde la perspectiva que proponemos, las tendencias de la vanguardia en Hispanoamérica deben ser comprendidas dentro de un proceso más amplio de renovación que se generaliza a partir del término de la Primera Guerra Mundial en el continente. El Vanguardismo pasa a ser entendido así como un aspecto de la renovación postmodernista. Pero este mismo proceso de renovación que comprende al Vanguardismo, debe a su vez ser comprendido dentro de un proceso de cuestionamiento crítico más general, que se relaciona tanto con la crisis por la que se atraviesa en ese momento como con el ascenso de nuevos sectores sociales que buscan incorporarse críticamente a la vida económica, política y cultural del continente.

Este marco general en que se inserta el florecimiento de las tendencias vanguardistas se prolonga aproximadamente en las mismas condiciones hasta 1930, que es el momento en que repercute con toda su fuerza en América Latina la crisis económica mundial de 1929. Las condiciones generales cambian y el desarrollo de las tendencias vanguardistas sufre también un cambio, que es lo que permite reconocer un segundo momento o período que se prolonga hasta los inicios del 40 o el comienzo de la Segunda Guerra. Por eso mismo, el estudio del segundo período dentro de la evolución del Vanguardismo hispanoamericano amerita un análisis en capítulo separado que permita también comprenderlo dentro de las nuevas condiciones históricas en que se desarrola.

Centro de Estudios Latinoamericanos "Rómulo Gallegos"

Caracas, 1980 